\title{
The Impact Analysis of International Trade Theory and Practice Teaching on College Students' Foreign Trade Entrepreneurship As an Example of Jiujiang University
}

\author{
Guoqing Xu, Jia Liu \\ Department of international trade, Business school, Jiujiang University, Jiujiang, China
}

\begin{abstract}
According to the reforming and opening, China's international trade has progressed rapidly; and under this development, there are many shock troopers going into this business, especially including many college graduates. These college graduates, after leaved out their mother college, some people selected to have a job about the international trade, some people selected to Start a Business of international trade, directly used their learning to expand the relationship between persons and to product or sale their own products. In this passage, the researching contents are analysis the teaching on the graduates' starting a business of international trade.
\end{abstract}

Key words - International trade theory and practice, teaching, college graduates, stating a business of international trade

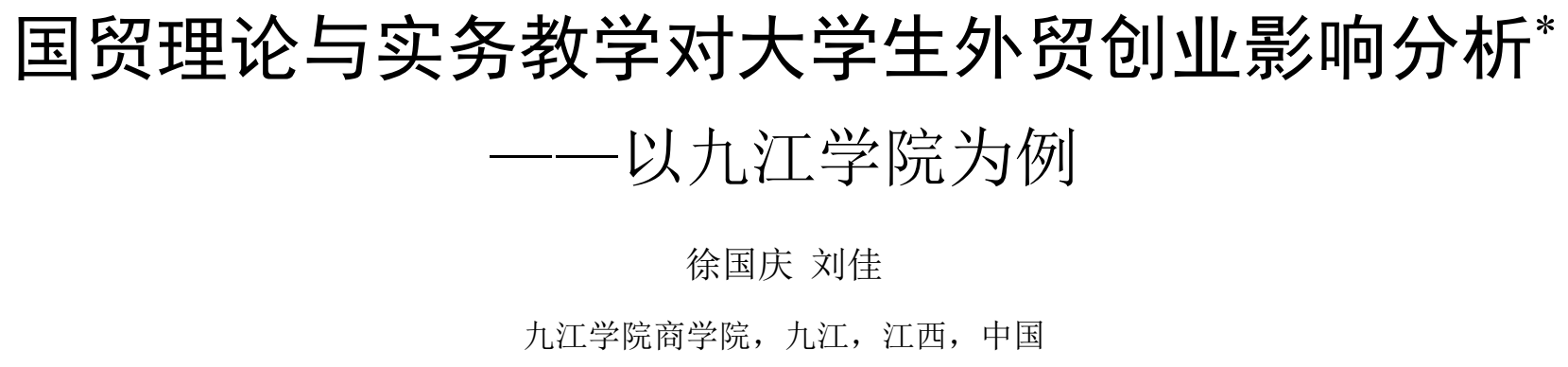

摘 要 伴随着改革开放后, 中国的国际贸易取得了飞速发展; 在这些发展的背后, 有许多时代的弄潮儿投入其身, 其中就包括 有众多的高校毕业生。这些刚刚走出校门的毕业生, 有的选择相关外贸行业, 直接去就业; 也有的, 在毕业后, 选择了外贸创业, 直 接用自己的所学, 来拓展人际关系, 来生产、销售自己的产品。本文所研究的内容, 即是从此国际贸易理论与实务的教学角出发, 探 讨分析该教学对毕业生外贸创业的影响。

关键词 国际贸易理论与实务, 教学, 高校毕业生, 外贸创业

1. 引言

在 20 世纪 90 年代中国高校扩招后, 各高校的国际贸 易专业不断出现, 截止到 2013 年 6 月份, 全国共有 730 余 所本科院校开设了国际贸易专业, 其所培养的毕业生也不 断增加, 自 2000 年 9 月到 2013 年 6 月, 全国高校所培养 的该专业学生 (不包括双学位学生) 共计约 190 万人, 如 此规模的大学毕业生, 在一方面, 为我国不断发展的对外 经济贸易注入了持续发展的新鲜血液和动力, 另一方面, 针对高校开设的国际贸易理论与实务课程, 其所起的作用
也不再是入门级的启蒙教材, 更多的是紧跟上了时代步伐, 也促进了大学毕业生自主创业的热情和投身实践。

当前国际贸易理论与实务课程的教学, 一则从介绍、 讲解最经典、最前沿的理论出发; 二则从当前实际所需的 国际贸易技能出发, 培养能真正动手操作的准工作人员。

在这些普通高校的国贸教学中, 由于不同任课教师的 差异, 学生平均学习能力、层次的差异, 所选择教材、教 学辅助材料的差异, 以及相关实习基地的有无等差异, 造 成了最终所培养学生的专业学习效果的差异, 也在很大程

“本文系 2012 年江西省高等学校大学生创新创业计划项目 “大学生手工艺品贸易平台搭建与拓展研究” 的前期研究成果。 
度上导致了学生所选择的就业方式一一是直接参与就业工 作还是选择实践性、创新性更强的创业。在不同高校的毕 业生中, 有不同的就业局面, 自 2008 年至今, 从江西省九 江学院毕业的近 2100 名本专科毕业生中, 有近 50 名学生, 选择了毕业后直接创办相关外贸类企业, 而据江西省内其 他地区高校的统计数据, 明显低于此数据, 但是与沿海发 达地区, 如江苏、浙江、上海、广东等地的高校毕业生相 比, 此数据又明显过低。

\section{2. 国际贸易理论与实务教学的现状}

在当前国际贸易理论与实务的教学过程中, 针对全国 不同地区所选择的形式有很大的差别, 有些高校为了追求 片面的扩招与发展, 采用一种粗放式的教学, 大班集中授 课, 教师考核松散, 学期末考试形式简单, 考试内容不能 契合所学, 最终形成教师授课简单应付、学生上课学习效 果低下、考核完全偏离主旨的模式; 而有一些高校, 由于 其发展历程中的经验, 采用了小班授课的模式, 规范教师 授课的行为, 一些有责任心的教师, 也不仅仅是应付授课, 能完全给学生讲解国际贸易理论与实务知识的主旨和要 领, 这些教师的期末考核也比较注重其自身的教学效果, 结合所教进行考核, 结果自然是提高了很多学生的学习积 极性和以后投身实践的良好愿望。

特别是在国际贸易实务知识的教学过程中, 有些高校 的思考非常周到, 无论是相关任课师资的选择, 还是实验 室的硬件、软件建设, 以及实习基地、实践工厂的选择, 无处不是为学生着想, 笔者所在的这所高校以及全国其他 很多高校, 都是这么安排和做到的, 结果自然是激发了很 多学生的学习热情和创业思维。

\section{3. 国贸专业大学生就业与创业现状}

不断发展的实体经济, 注入了源源不断的大学毕业生, 一方面给企业带来了人才的补给; 另一方面, 也有效的检 验了大学生所学, 使得其能 “学以致用”。在这些过程中, 相关国贸专业的毕业生, 有为数众多的人, 走上了从事国 际贸易方面的具体工作, 涉及相关的外销、跟单、单证、 报关、报检、货运等不同行业的工作, 当然, 也有一部分 没有找到工作或是从事其他专业的工作, 综合言之, 仅有 小部分选择了创业, 但是这些小部分的人, 确实通过自己 的努力, 抓住了这个时代所赋予的经济发展、网络网易的 机遇, 成就了一个又一个实体经济的开创者。

从 2008 年至今九江学院不同年份的数据中可见, 在相 关的国贸专业毕业生中, 每年有近 30-70\%的学生, 从事的 是与外贸相关的工作, 也有近 5-10\%的学生选择了外贸创 业, 详见下表一所示:
表一：九江学院 2008-2013 年国贸毕业生外贸就业/创业统计表

\begin{tabular}{|c|c|c|c|}
\hline 年份 & 毕业生人数 & $\begin{array}{c}\text { 外贸就业人数/就 } \\
\text { 业率 }\end{array}$ & $\begin{array}{c}\text { 外贸创业人数/创 } \\
\text { 业率 }\end{array}$ \\
\hline 2008 & 390 & $145 / 37.18 \%$ & $10 / 2.56 \%$ \\
\hline 2009 & 368 & $169 / 45.92 \%$ & $8 / 2.17 \%$ \\
\hline 2010 & 340 & $172 / 50.59 \%$ & $11 / 3.24 \%$ \\
\hline 2011 & 320 & $196 / 61.25 \%$ & $8 / 2.50 \%$ \\
\hline 2013 & 359 & $162 / 45.13 \%$ & $5 / 1.39 \%$ \\
\hline
\end{tabular}

资料来源：以上资料经该校学生就业相关部门整理所得, 2013 年 6 月 25 日。

通过上表可见, 在近年来的外贸专业毕业生就业中, 外贸方向也并非是最主要的方向, 这些跟我国的经济、贸 易发展形势是紧密相关的, 当经济形势不断向好时, 所需 的外贸人才会相对比较多, 选择创业的毕业生也相对会比 较多, 但是创业与就业相比, 除了受到外部经济环境的因 素外, 最重要的影响因素应该还是本人的心里因素, 即该 生对自己的创业愿景与心理预期的强弱, 如 2008 年, 总体 上外贸就业形势并不大好, 但是仍然有高达 $2.56 \%$ 的国贸专 业毕业生选择了外贸创业。从此表中, 也可看出, 自 2010 年以后, 大学生外贸创业, 其相对比例还是处于下降状态 的, 说明当前大学生外贸创业, 无论是在行动方面还是在 心理方面, 可能存在一定的谨慎或担忧心态。

\section{4. 国贸理论与实务教学对大学生外贸创业的有利影 响}

在当前的国贸实务教学中, 对于大学毕业生的外贸创 业方面, 也有一些积极的影响, 具体表现在以下一些方面:

4.1 通过对国际贸易理论知识的讲解, 能提高学生对整体国 际贸易的认识

在当前国际贸易的教学过程中, 一般开设此国际贸易 专业的本科院校, 会选择在大二上学期或下学期讲授《国 际贸易理论》这门课程, 该课程对此专业的学生理解国际 贸易的涵义、内容、对象、层次以及发展, 有较系统和深 入的讲解, 与之相关的还有一门《国际经济学》, 这门课程, 从更宏大的层面上, 将国际经济活动从微观和宏观方面进 行了讲解, 对于形成学生更全面准确地理解国际贸易活动 及发展, 有一定的帮助作用。

4.2 通过讲授具体的贸易实务知识, 能使学生更熟悉相关外 贸流程

通过教师的课堂授课、实验室授课以及到企业或码头 现场参观学习等方式, 讲解国际贸易实务的现状、流程、 
相关处理内容以及善后处理等方面, 能更好地帮助毕业生 学习国际贸易实务知识, 也能让学生更全面、系统地了解 毕业之后的外贸相关工作会干什么, 以后自己创业了, 该 怎么运作企业, 如何与海关、检验检疫部门、商务部门、 外汇管理部门、外国进出口商打交道。

4.3 通过讲授与国际贸易相关方面的知识, 能促进学生形成 系统、全面的知识体系

在整个国际贸易实务知识体系的教学过程中, 虽然国 际贸易理论和实务的教学知识相对最重要, 但是与之相关 的一些知识, 如外语、商品学、人际沟通、礼仪等相关知 识, 也在一定程度上会影响毕业生的判断, 故这些与贸易 实务相关的课程如《外贸英语函电》、《外贸商品学》、《涉 外人际沟通》、《涉外礼仪》等相关课程, 在很大程度上弥 补了贸易实务知识的不足, 能更好地帮助学生, 形成全面、 系统的外贸理论与实务知识框架体系。

4.4 通过教师或学校安排的外贸实践, 极大地锻炼了学生动 手操作的能力

国内有很多高校, 都会选择相关外贸实践的方式, 提 高学生的学习兴趣或检验课堂教学, 这些实践, 种类很多, 有暑期校外的实践, 还有平时的一些实践教学周, 安排学 生去往大型外贸公司参观学习, 无论采用哪种方式, 督促 学生静下心来学习, 对他们的帮助作用都很大。

\section{5. 国贸理论与实务教学对大学生外贸创业的不利影 响}

在当前的国际贸易教学过程中, 虽然课堂所学在一定 程度上能帮助学生学有所成, 运用学习的内容指导日后的 工作, 但是, 也确实存在一些不利影响, 导致了学生创业 激情的消散:

\section{1 部分高校在硬件上的配备不足, 导致学习效果不佳}

目前, 中国不同的高校, 由于财力的不同, 以及教育 系统内部的㽽疾, 导致一些高校院系的国贸专业徒有虚名, 并无其实, 无论是师资, 或是教学环境及设施, 还是实践、 实习基地, 有的学校甚至没有电脑操作机房, 没有实践、 实习教育基地, 可想而知, 更多的是一种书本的灌输。也 有的高校院系, 虽然教学师资、设施、基地, 都属一流, 但是学校不重视, 所教育的学生, 其动手能力并不强, 这 背后其实更多地是教育者本身的问题, 没有能做到认真去 教育, 负责任地去教育。这些现象, 最终也是导致了我国 部分高校或院系培养出来的国贸毕业生, 无甚竞争力, 丧 失了对国际贸易的热爱, 自然也谈不上在这个方面去创业,
搏击一把。

5.2 部分高校在软件上的滞后, 导致落后于形势

应该来说, 国际贸易无论是理论还是实务的更新, 都 是比较快的, 时下比较流行的方向早已不是传统的那些国 际贸易理论和国际贸易结算、支付方式了, 但是在一些高 校院系里面, 还是存在着用十年前的教学大纲和教案的现 象, 而且这是比较普遍的一些现象; 有些教材严重脱离现 实, 居然还能一版再版, 其凭借的固然不是优良的质量, 而是与出版社、与高校之间的合作协议, 导致其 “被欢迎” 了; 一些学校, 几年来, 都没有顶尖的专家学者来校就国 际贸易理论与实务知识讲学的, 甚至连校内的专家学者都 没有这个方面系统、深入的讲学; 一些与贸易有关的推广 性纪录片, 如《大国贸易》、《人民币》、《黄金》、《历代经 济变革得失》等, 以及一些世界顶尖院校贸易类的公开课, 在很多学校根本没有走上课堂, 甚至连授课教师都不知道, 其所传授的知识, 自然不具有时新性, 也不具有深刻性, 这样做, 最终是误了学生的兴趣, 也导致了很多毕业生不 会在这个方面选择创业。

5.3 讲授者简单应付, 学习者索然无味, 最终唯恐避之不及

当前的教师队伍, 应该来说, 总体上, $80 \%$ 以上的人, 还是兢兢业业, 克忠职守的, 所讲授的内容, 无论正确性 还是时新性上, 都是把握的比较好的, 但是几乎每所学校, 都存在着一些教师, 并不能从整体上把握所授课程知识的 连贯性, 很多时候, 就是简单应付或者照搬别人的思想, 导致了学习者也是学得索然无味——不如自己看书好了, 结果培养出了一大批接受能力很强, 但是思维极度缺乏的 毕业生; 很多高校的平时作业、期末考试、毕业论文, 也 都是走走过场, 形式主义而已, -----; 这些现象的发生, 固然与 1998 年扩招之后的事实有关, 但却是直接导致了很 多国贸本科毕业生的专业水平极端低下, 很多毕业生谈不 上对国际贸易的兴趣, 也只是简单的应付而已, 可想而知, 这些人, 怎么会选择一个自己不感兴趣的行当去创业呢?

5.4 国贸教学与现实脱节性及片面性, 导致毕业生外贸创业 遇挫

从绝大多数高校国贸教学的现状来看, 应该还是紧跟 时代的, 无论是选取的教材, 还是所使用的教学软件, 实 习基地的搭建, 但是也依然存在着一些高校或院系或教师, 在教学过程中的教学内容的滞后性, 不能紧跟当前外贸发 展的主流趋势, 不能全面合理地把握当前外贸发展, 在教 学过程中, 自然存在着一定的滞后性也存在着一定程度上 的片面性, 如一位教师在讲解贸易救济措施时, 很显然应 
该提及今天欧盟与中国之间的贸易战, 包括光伏产品、葡 萄酒、特殊钢管等产品, 在分析是什么原因造成贸易救济 措施时, 很显然应该从贸易、经济、政治、外交、地缘、 军事、历史、习俗等等方面去分析的，也只有多考虑到了， 才能全面, 也只有这样联系最新实际、全面分析, 毕业生 才会渐渐感兴趣, 也才能最后选择自己的兴趣所在, 去创 业, 也才能不被那些疏忽的细小因素所打败。

\section{6. 国贸理论与实务教学改进对毕业生外贸创业的促进作用}

认识到当前国贸教学过程中存在的问题, 我们每个人 都去努力纠正这些问题, 应该来说, 对毕业生外贸创业的 帮助作用还是会比较大的, 具体来说, 应该有以下几个方 面:

\section{1 提高硬件配置, 提升学生学习效果}

由于外贸实务课程的操作性, 首先自然需要高校配备 齐全的电脑机房以及相关的模拟沙盘; 其次, 一些良好的 校内或校外实习基地的构建, 对于学生们的学以致用, 帮 助作用也是挺比较明显的, 这自然会提升学生们学习的兴 趣; 学校实习基地的构建与完善, 一定程度上能发挥学校 实践教学的积极作用, 同时也能在很大程度上, 调动学生 学习并应用课堂所学的积极性, 这些对提高学生创业积极 性, 有很好的引导作用。

\section{2 突出软件升级, 紧跟时代前沿}

软件的升级包括许多方面, 既涉及到教学主体所需的 软件, 也涉及到教学过程中所需的软件。既需要提升外贸 教学教师队伍的业务素质, 也需要提升其不断钻研开拓的 精神; 同时也要求在教学过程中, 无论是所选用的教材、 课辅、教学软件, 还是所适用的教学大纲、教案之类的, 都要求要及时升级、更新, 结合最新的研究及应用方向。 同时, 更要不断 “请进来” 和 “走出去”, 开展多边交流, 邀请全国知名的相关专业学者来校讲学, 本校知名的一些 教师, 也可以讲学交流, 通过这些交流所获得的信息, 既 能在一定程度上帮助教师提升专业视角, 也在很大程度上 能帮助学生更新知识和开拓视野范围, 进而培养其创业思 维。

\section{3 突出实践教学，提升教师教学热情}

由于理论研究与实践应用在一定程度上的脱节, 导致 了部分高校与院系的国贸教学存在着重理论轻实践的情 况, 为了避免这种不利局面的产生, 就要求相关院系应该 多开设实践课, 强调动手, 而不是停留在书本上, 这样既 能避免照本宣科或者流于应付式的教学, 又能真正提升学
生的学习兴趣和实际能力。由于扩招的后遗症, 导致很多 高校出现了人才培养的规模化趋势, 在这种趋势下, 每个 学生被视作一种近乎同质的商品, 集中授课, 集中考试, 粗放式的培养与教育, 最终导致了所培养的学生虽然是比 较有个性, 但是在学习思考上确实缺乏一些最基本的思维, 很多简单的工作都难以胜任, 也难怪有人惊呼 “五年前的 硕士, 只相当于今天的本科; 五年前的本科, 只相当于今 天的专科”。应对这种局面, 固然需要考量高校的生存问题, 但是更不容忽视的是在校生的培养质量, 需要的是学校上 上下下, 充满热情的投身教育, 创作美好的教学、生活环 境, 特别是教学者要 “学高为师、身正为范”, 为每位受教 育者提供良好的教学氛围, 传授切合时代、具有应用价值 的 “道业”。

6.4 突出国贸教学的创新性与全面性, 引导学生积极创业

在国贸教学过程中, 需要的不仅仅是讲授或演示书本、 软件、教辅上的一些内容, 更要求教学者能根据这些知识, 结合实际应用, 有所创新; 对于很多贸易理论与实务中现 状及问题的分析, 也不能简单只依照书本或媒体上的评论, 更重要的是结合所学, 发挥思考空间, 拓展思维能力, 进 行全面而具体的分析, 这样才能更好更有效地提升学生的 学习思维能力, 最终, 也才能促进其创业积极性的提升。

\section{7. 结论}

在分析国贸实务教学对外贸创业的有利影响、不利影 响及教学改革的促进作用后, 可以清晰可见, 无论是哪所 高校, 只要自身想真正提升学生的外贸就业能力与创业水 准, 势必会对管理者层次、教师队伍、教学内容、教学模 式、教学方法等进行不断地更改, 以达到发挥优势、发展 特色、形成能力、强化特长、勇于创业的良性发展模式, 相信在不远的未来, 随着我国国际贸易规模和层次的提升, 我们国贸方向的教学会更加有特色, 所培养的人才会更具 竞争力和创造性。

\section{参考文献 (References)}

[1] Juan Zhang. How they go to success in their Starting a Business of international trade. International Market, 2006(3):32-35.

[2] Jiexiang $\mathrm{Xu}$, Xiaobing Xing. The way of improving imitated teaching efficiency in International Trade Practice. The teaching of China's college, 2011(6):86-88.

[3] Jun Ma, Ping Ran. The talk on the education of quality and ability of college students' entrepreneurship. Career Horizon, 2011(12): 21-24.

[4] Yan Fang. The talk on the new characteristic of Starting a Business of international trade in the new ear. The guided journal of China's economic and trade. 2012(1):15-18. 